Cadernos de

ESTUDOS LINGǘĺsTICOS - (57.2), Campinas, Jul./Dez. 2015

\title{
SUBSTANTIVOS E VERBOS DA LÍNGUA ITALIANA EM CONTRASTE COM O PORTUGUÊS: REFLEXÕES PARA UMA PEDAGOGIA DOS VOCÁBULOS HETEROTÔNICOS
}

\author{
MARILEI AMADEU SABINO \\ UNESP \\ MICHELLI GLAUCE DEVECCHI \\ UNESP
}

\begin{abstract}
RESUMO: O objetivo desta análise é mostrar como seis dicionários bilíngües registram informações referentes a unidades lexicais que são graficamente semelhantes, no português e no italiano, mas cujas sílabas tônicas são diferentes. Essa estratégia de sinalizar a sílaba tônica, principalmente dos verbos heterotônicos conjugados, apesar de não requerer tanto espaço físico e de ser de fundamental importância nas obras bilíngües italianas, por facilitar a elaboração de atividades de sala de aula, ainda é muito pouco explorada.

Palavras-chave: Heterotônicos; dicionários bilíngues; pedagogia do léxico.
\end{abstract}

\begin{abstract}
The aim of this paper is to show how six bilingual dictionaries record information regarding lexical units that are graphically similar, in Portuguese and Italian, but whose stressed syllables are different. This strategy of signaling the different stressed syllable, especially of the verbs conjugated in same tenses, despite not requiring much space and being of fundamental importance in bilingual Italian-Portuguese dictionaries, by facilitating the development of classroom activities, it is still very little explored.
\end{abstract}

Keywords: Different stressed syllable; bilingual dictionaries; lexis pedagogy.

\section{INTRODUÇÃO}

Nos últimos tempos, graças aos avanços tecnológicos que propiciaram aos dicionaristas e lexicógrafos uma diversidade de equipamentos e programas, houve uma evolução no fazer dicionarístico, já que, com a diminuição do trabalho braçal, os lexicógrafos dispõem de mais tempo para refletir sobre os fatos lingüísticos, assim como para encontrar melhores soluções.

Contudo, nenhum dicionário consegue ser exaustivo, devido à própria natureza da língua que não permite que lhe seja feita uma descrição completa. Nesses termos, o lexicógrafo deve fazer uma seleção adequada, coerente e homogênea, tanto da macroestrutura da obra, quanto das demais informações que 
irá privilegiar, referentes não só ao sistema, mas também à norma e à fala (Coseriu, 1978), quando for relevante.

Obviamente, o público tende a privilegiar as obras que, além de esclarecer o sentido das lexias presentes nos verbetes, fornecem o maior número de informações pertinentes ao uso que pretende fazer do dicionário, tais como transcrição fonética, sílabas tônicas, categorias gramaticais, marcas de uso, fraseologia - para citar apenas algumas.

Quando se estuda uma língua estrangeira (LE), é indiscutível a necessidade de aprendê-la em seus diversos níveis: fonológico, morfológico, sintático, semântico e pragmático. Nesse sentido, os dicionários, especialmente os bilíngues, desempenham papel fundamental.

AMARAL (1995), em sua tese de doutorado, faz uma análise crítica de dicionários escolares bilíngües espanhol-português, mostrando suas várias limitações e apresentando sugestões que contribuem sobremaneira para um enriquecimento de sua qualidade, dentre as quais o acréscimo de informações referentes à grafia, aos sentidos dos fraseologismos, a marcas de uso que identificam as unidades léxicas heterossemânticas (falsos cognatos/ falsos amigos) e outras.

Sabe-se que o uso errôneo da língua estrangeira, por parte do aprendiz, em qualquer um daqueles níveis citados, revela, de imediato, seu grau de (in) competência nesse idioma. Isso pode acarretar-lhe conseqüências desagradáveis, tanto no seu próprio país de origem - enquanto aprendiz dessa língua estrangeira quanto no país onde essa língua estrangeira é o idioma nativo - seja na condição de aprendiz, seja na de profissional atuante. Algumas dessas conseqüências podem ser arroladas, levando-se em conta, respectivamente, os dois contextos mencionados. Esse falante pode:

- Ser visto pelos professores e colegas de curso como um aprendiz de baixa proficiência lingüística na LE;

- Ser tachado de aluno displicente e desatencioso em relação ao estudo da LE que por isso, está sempre cometendo os mesmos erros;

- Ser rotulado de aluno "sem dom" para as línguas estrangeiras e, em conseqüência, apesar de seus supostos esforços, de nunca conseguir internalizar as regras e estruturas da LE;

- Ser imediatamente identificado como estrangeiro, pelo falante nativo da LE;

- Sofrer as discriminações comuns, que muitas vezes o estrangeiro sofre, pelos falantes nativos, em maior ou menor grau, dependendo da cultura em que está inserido. Em se tratando de países nos quais grande parte dos nativos são xenófobos, a discriminação é visivelmente perceptível;

- Nunca chegar a possuir uma competência ótima, bem próxima à do falante nativo (near native speaker competence) e, consequentemente, 
- Nunca poder sentir o orgulho de passar por falante nativo, sob a ótica dos próprios nativos, no país estrangeiro;

- Ser mal compreendido ou mal interpretado, podendo vir a ter problemas com o seu interlocutor, dependendo do caso. Com um exemplo grosseiro, poderíamos ilustrar a tese: No caso da frase: Questi principi sono belli (estes princípios são bonitos), se por um lapso ocorrer, por parte do aprendiz, a pronúncia tônica na primeira sílaba, Questi principi sono molto belli, a compreensão seria outra (estes príncipes são muito bonitos).

- Em suma, ser considerado um mau profissional.

Este exemplo (principi e principi), embora não seja muito representativo do aspecto do qual estamos tratando - uma vez que as sílabas tônicas tanto da palavra príncipe, quanto da palavra princípio, em português, são coincidentes com as do italiano -, serve para ilustrar, ainda que parcialmente, a problemática que estamos abordando.

Desse modo, com base no que foi exposto, esse estudo tem por objetivo enfatizar a importância de aprimorar o nível fonológico na LE, especificamente no que se refere às sílabas tônicas diferentes, em unidades lexicais graficamente semelhantes no português e no italiano. Esse aspecto divergente, nas duas línguas, gera, com muita constância no dia-a-dia da sala de aula de língua italiana, para aprendizes brasileiros, inúmeros desacertos quanto à tonicidade das palavras, principalmente quando os alunos estão envolvidos em atividades de leitura ou mesmo de produção oral.

Por essa razão, neste trabalho serão tratados os substantivos e os verbos da língua italiana que são heterotônicos no infinitivo e em alguns tempos verbais, em comparação com a língua portuguesa. Nessa perspectiva, partimos em busca de analisar alguns dicionários bilíngües e monolíngües, a fim de sabermos como cada um deles trata essa problemática. Os dicionários consultados foram: o de Giuseppe Mea (MEA), o de Spinelli e Casasanta (SPI), o de Parlagreco (PAR), o de Amendola (AMEN), o da editora Michaelis (MI), e o da Zanichelli (ZAN), todos bilíngües; o de Zingarelli e o de Devoto e Oli (monolíngües) ${ }^{1}$. Contudo, apesar da consulta feita aos dicionários monolíngües, restringiremos a nossa análise, presente nos quadros 1, 2 e 3, especialmente aos dicionários bilíngües, que serão o principal alvo das nossas discussões.

A partir dessa análise, portanto, pretendemos fornecer subsídios teóricos e práticos que visam otimizar o tratamento dado aos heterotônicos italianos, seja em dicionários bilíngües, seja nos contextos de sala de aula de língua italiana. trabalho.

${ }^{1}$ Por razões de espaço, as siglas apresentadas entre parênteses serão utilizadas nas tabelas deste 


\section{SUBSTANTIVOS E VERBOS HETEROTÔNICOS NOS DICIONÁRIOS BILÍNGÜES E MONOLÍNGÜES}

O objetivo primeiro desta seção, dividida em três subitens, é investigar como os dicionários monolíngues e bilíngues tratam a questão da tonicidade nos substantivos e verbos da língua italiana. No que respeita aos verbos, além daqueles cuja diferença de sílaba tônica se encontra em sua forma infinitiva, há também outro grupo que se destaca por apresentar divergência de tonicidade nos tempos Presente do Indicativo, Presente do Subjuntivo e Imperativo, nas $1^{\text {as }}, 2^{\text {as }} \mathrm{e}$ $3^{\text {as }}$ pessoas do singular e $3^{\text {as }}$ do plural (com exceção da $1^{\text {a }}$ pessoa do Imperativo, que é inexistente).

\subsection{O tratamento dado nos dicionários aos verbos heterotônicos no infinitivo}

Os dicionários monolíngües, em geral, registram a sílaba tônica de todo e qualquer verbo da língua no infinitivo, incluindo, portanto, também aqueles que são heterotônicos no italiano, em relação ao português. No que diz respeito aos dicionários bilíngües, constatamos que a sílaba tônica dos verbos heterotônicos, no infinitivo, também vem marcada em quase $100 \%$ dos casos consultados, com base na lista que aleatoriamente escolhemos para fazer parte do nosso corpus $^{2}$. Essa freqüência, praticamente total, foi verificada nos seis dicionários bilíngües já mencionados, como podemos observar abaixo ${ }^{3}$ :

\begin{tabular}{|c|c|c|c|c|c|c|c|}
\hline \multicolumn{8}{|c|}{ HETEROTÔNICOS (verbais: Infinitivo) } \\
\hline \multicolumn{2}{|c|}{ Heterotônicos verbais } & Zan & Mi & Amen & Par & Spi & Mea \\
\hline Italiano & Português & & & & & & \\
\hline Ammettere & Admitír & + & + & + & + & + & + \\
\hline Apprendere & Aprender & + & + & + & + & + & + \\
\hline Cogliere & Colher & + & + & + & + & + & + \\
\hline Condurre $^{4}$ & Conduzir & + & + & + & - & - & + \\
\hline Conoscere & Conhecer & + & + & + & + & + & + \\
\hline Correre & Correr & + & + & + & + & + & + \\
\hline Crescere & Crescer & + & + & + & + & + & + \\
\hline
\end{tabular}

${ }^{2} \mathrm{O}$ Mea marca a sílaba tônica na transcrição fonética do vocábulo. O Zan registra a sílaba tônica na própria entrada, com um pingo minúsculo debaixo da vogal acentuada. O Mi, do mesmo modo que o Mea, registra a tonicidade da unidade lexical na transcrição fonética da mesma. O Amen usa discretos acentos graves, agudos e circunflexos para marcar a sílaba tônica. O Par registra um acento grave em cima da vogal tônica, muito discretamente perceptível. Quando o acento é na vogal i, quase se confunde com o pingo e passa desapercebidamente. E o Spi marca a sílaba tônica também na própria entrada, com um acento agudo.

${ }^{3} \mathrm{O}$ sinal de + significa que a sílaba tônica do verbo em questão está registrada no referido dicionário.

${ }^{4}$ Apenas o Par e o Spi deixaram de registrar a tônica em um único verbo (condurre), mas isso pode ser devido ao fato de ser um vocábulo paroxítono, e, portanto, sem a necessidade de ser marcado, segundo os critérios adotados por alguns dicionaristas. 
(adernos de ESTUDOS LINGḯlsTICOS (57.2) - Jul./Dez. 2015

\begin{tabular}{|c|c|c|c|c|c|c|c|}
\hline Distinguere & Distinguịr & + & + & + & + & + & + \\
\hline Distrugggere & Destruir & + & + & + & + & + & + \\
\hline Esplodere & Esplodir & + & + & + & + & + & + \\
\hline Mettere & Meter & + & + & + & + & + & + \\
\hline Nascere & Nascer & + & + & + & + & + & + \\
\hline Prendere & Prender & + & + & + & + & + & + \\
\hline Proteggere & Proteger & + & + & + & + & + & + \\
\hline Raccogliere & Recolher & + & + & + & + & + & + \\
\hline Rogdere & Roẹr & + & + & + & + & + & + \\
\hline Rompere & Romper & + & + & + & + & + & + \\
\hline Riflettere & Refletir & + & + & + & + & + & + \\
\hline Scrivere & Escrever & + & + & + & + & + & + \\
\hline Vendere & Vender & + & + & + & + & + & + \\
\hline
\end{tabular}

Vejamos, em seguida, qual é o tratamento que esses seis dicionários bilíngües mencionados dão aos nomes (no caso deste artigo, só os substantivos).

\subsection{O tratamento dados aos substantivos heterotônicos nos dicionários}

Semelhantemente aos verbos no infinitivo, verifica-se que o registro das sílabas tônicas também ocorre com freqüência no caso dos nomes (substantivos) que figuram como entrada nos dicionários monolíngues e bilíngues. Observe-se:

\begin{tabular}{|c|c|c|c|c|c|c|c|}
\hline \multicolumn{8}{|c|}{ HETEROTÔNICOS (nominais) } \\
\hline \multicolumn{2}{|c|}{ Heterotônicos nominais } & Zan & Mi & Amen & Par & Spi & Mea \\
\hline Italiano & Português & & & & & & \\
\hline Agenzia & Agệncia & + & + & + & + & - & + \\
\hline Bisturi & Bisturi & + & + & + & + & + & + \\
\hline Canguro $^{5}$ & Canguru & + & 0 & + & 0 & - & + \\
\hline Cinema & Cinema & + & + & 0 & + & + & + \\
\hline Classifica & Classificação & + & 0 & + & 0 & + & + \\
\hline Fasscino & Fascínio & + & + & + & + & + & + \\
\hline Limite & Limite & + & + & + & + & + & + \\
\hline Microfono & Microfone & + & + & + & + & + & + \\
\hline Oceano $^{6}$ & Oceano & + & + & $-*$ & + & + & + \\
\hline Ombelico & Umbigo & + & + & + & - & - & + \\
\hline Ossigeno & Oxigênio & + & + & + & + & + & + \\
\hline Polizía & Policia & + & + & + & - & - & + \\
\hline Sigaro (=charuto) & Cigarro $^{7}$ & + & + & + & + & + & + \\
\hline
\end{tabular}

${ }^{5}$ A marca 0 significa que o dicionário não registra aquele item lexical.

${ }^{6} \mathrm{O}$ amen registra a tônica do vocábulo oceano, de forma errada, igual à sílaba tônica da língua portuguesa.

${ }^{7} \mathrm{O}$ vocábulo italiano sigaro significa charuto, em português, mas é um vocábulo heterotônico, se comparado com cigarro, cognato enganoso em relação à língua italiana. 
SABINO \& DEVECCHI - Substantivos e verbos da língua italiana em contraste com o português...

\begin{tabular}{|ll|c|c|c|c|c|c|}
\hline Teleffono & Telefone & + & + & + & + & + & + \\
\hline Tempesta & Tempestade & + & + & + & - & - & + \\
\hline Visita & Visita & + & + & + & + & + & + \\
\hline Yogurt & Iogurte & + & + & - & 0 & 0 & + \\
\hline
\end{tabular}

Quanto aos heterotônicos nominais, a marca da sílaba tônica, nos monolíngues, ocorre em 100\% dos casos, enquanto que nos bilíngües é registrada em porcentagens menores. Verifica-se que o Mea e o Zan registram todos os 17 itens listados (100\%). O Mi registra 15 deles (88,2\%), o Amen $14(82,3 \%)$ e por fim, o Par e o Spi que registram apenas 11 (64,7\%). Observou-se que os substantivos heterotônicos, embora nem sempre marcados nos dicionários bilíngües, quando o são, ou é por meio de acentos graves, agudos ou circunflexos na sílaba tônica do vocábulo (Par, Spi e Amen ), ou através de marcas na transcrição fonética da unidade lexical (Mea e $\mathbf{M i})$.

Percebe-se então, pelo quadro apresentado, uma sistematicidade razoável no registro das sílabas tônicas dos nomes (substantivos) e dos verbos no infinitivo, nos dicionários bilíngües investigados. Isso porque é de praxe, tanto nos dicionários monolíngues quanto nos bilíngues, marcar a tonicidade de toda e qualquer unidade lexical que seja a entrada de um verbete, seja qual for a sua categoria gramatical, conforme se observa na nota 2 deste artigo.

No entanto, resta ainda um problema, que pode ser considerado um grande obstáculo para os aprendizes de língua italiana, cujo idioma nativo é o português. Refere-se a saber identificar e pronunciar com precisão os tais verbos e substantivos heterotônicos no italiano, em relação ao português. Isso se deve ao fato de que nem sempre o aprendiz tem à mão um dicionário para consulta, e também porque, para o desenvolvimento de qualquer atividade em classe, proposta pelo professor, seja de leitura ou de produção oral, não é comum, metodologicamente falando, esperar que o aprendiz faça uso imediato de dicionários, exatamente durante a realização desses tipos de tarefas.

Além disso, outro problema que se põe, no que tange ao bom domínio dos heterotônicos, por parte dos estudiosos de língua italiana, é que, seja nos dicionários monolíngues, seja nos bilíngues, eles estão diluídos em meio a milhares de outras unidades lexicais, muitas das quais são graficamente (quase) idênticas a verbos e nomes da língua portuguesa e que, no entanto, possuem a mesma sílaba tônica em ambas as línguas, ou seja, NÃO são heterotônicos. Diante disso ocorre-nos a seguinte pergunta: como resolver este problema? A esta pergunta procuramos responder no item 2 deste trabalho, bem como nas considerações finais.

Nesse momento, trataremos de alguns verbos que são heterotônicos apenas quando conjugados em alguns tempos verbais e somente em algumas pessoas.

\subsection{O tratamento dado nos dicionários a verbos conjugados que são heterotônicos em apenas algumas pessoas e em alguns tempos verbais}

Se os substantivos e verbos no infinitivo heterotônicos são frequentemente marcados nos dicionários monolíngues e bilíngües, o mesmo não acontece com os 136 
Cadernos de ESTUDOS LINGüÍSTICOS (57.2) - Jul./Dez. 2015

verbos que nas $1^{\mathrm{a}}, 2^{\mathrm{a}}$ e $3^{\mathrm{a}}$ pessoas do singular, bem como na $3^{\mathrm{a}}$ do plural do presente do indicativo, levam a tônica em uma sílaba diferente daquela que é acentuada em português. Cumpre-nos informar, também, que esses verbos são heterotônicos em relação ao português apenas na $1^{\mathrm{a}}, 2^{\mathrm{a}}$ e $3^{\mathrm{a}}$ pessoas do singular e na $3^{\mathrm{a}}$ do plural, não só do Presente do Indicativo, mas também do Presente do Subjuntivo. O mesmo procedimento vale para o Imperativo, com a diferença de que, nesse último caso, a primeira pessoa do singular não existe.

O procedimento de registrar essas variantes, no caso específico desses verbos, é considerado somente por dois dos seis dicionários bilíngües observados. São eles: o Mea e o Amen. O único a considerá-lo realmente com seriedade e sistematicidade é o Mea, já que os registra sempre, embora, provavelmente por um lapso, deixou de registrar um (único) deles, presente em nosso corpus. O Amen, por outro lado, só os registra esporadicamente. Observe-se:

\begin{tabular}{|c|c|c|c|c|c|c|c|}
\hline \multicolumn{8}{|c|}{ HETEROTÔNICOS (verbais: $1^{\mathrm{a}}, 2^{\mathrm{a}}, 3^{\mathrm{a}}$ pes. sing. e $3^{\mathrm{a}}$ pes. pl.) } \\
\hline \multicolumn{2}{|c|}{ Heterotônicos verbais } & Zan & Mi & $\mathrm{Amen}^{8}$ & Par & Spi & Mea \\
\hline Italiano & \multirow{2}{*}{$\begin{array}{l}\text { Português } \\
\text { acomodo }\end{array}$} & & & & & & \\
\hline Accomodo & & - & - & - & - & - & + \\
\hline Annuncio & anuncio & - & - & - & - & - & -9 \\
\hline Auguro & auguro & - & - & - & - & - & + \\
\hline Calcolo & calculo & - & - & + & - & - & + \\
\hline Carico & carrego & - & - & + & - & - & + \\
\hline Comunico & comunico & - & - & + & - & - & + \\
\hline Continuo & continúo & - & - & + & - & - & + \\
\hline Dedico & dedico & - & - & + & - & - & + \\
\hline Evito & evito & - & - & + & - & - & + \\
\hline Giustifico & justifico & - & - & + & - & - & + \\
\hline Imito $^{10}$ & imito & - & - & $-*$ & - & - & + \\
\hline Immagino & imagino & - & - & + & - & - & + \\
\hline Implico & implico & - & - & + & - & - & + \\
\hline Indico & indico & - & - & + & - & - & + \\
\hline Limito & limito & - & - & - & - & - & + \\
\hline Merito & mereço & - & - & - & - & - & + \\
\hline$\underline{\text { Odio }}$ & odeio & - & - & - & - & - & + \\
\hline Ordino & ordeno & - & - & - & - & - & + \\
\hline$\underline{\text { Ospito }}$ & hospedo & - & - & - & - & - & + \\
\hline Partecipo & participo & - & - & - & - & - & + \\
\hline Pettino & penteio & - & - & - & - & - & + \\
\hline Pratico & pratico & - & - & - & - & - & + \\
\hline
\end{tabular}

${ }^{8} \mathrm{O}$ Amen registra a conjugação da $1^{\mathrm{a}}$ ou das duas primeiras pessoas do presente do indicativo, de alguns verbos, ou ainda só a terminação da conjugação verbal da primeira pessoa, acentuada.

${ }^{9} \mathrm{O}$ Mea não registra a conjugação da primeira pessoa do singular unicamente desse verbo, o que leva a crer que se trata mais de um lapso do que de falta de sistematicidade.

${ }^{10} \mathrm{O}$ Amen registra a tônica deste vocábulo errada, igual à sílaba tônica da língua portuguesa. 
SABINO \& DEVECCHI - Substantivos e verbos da língua italiana em contraste com o português...

\begin{tabular}{|ll|c|c|c|c|c|c|}
\hline Preoccupo & preocupo & - & - & - & - & - & + \\
\hline Pubbblico & publico & - & - & - & - & - & + \\
\hline Rinuncio & renuncio & - & - & - & - & - & + \\
\hline Sémino & semeio & - & - & - & - & - & + \\
\hline Süpero & Supero & - & - & - & - & - & + \\
\hline Telefono & telefono & - & - & - & - & - & + \\
\hline Vísito $^{11}$ & visito & - & - & $-*$ & - & - & + \\
\hline
\end{tabular}

Com isso, obtivemos os seguintes resultados: das 29 unidades lexicais averiguadas, o Mea registra 28 (96,5\%) e o Amen registra 10 (34,4\%). Os demais não registram nenhuma.

Essa estratégia de sinalizar a sílaba tônica dos verbos heterotônicos conjugados é bastante interessante porque evita graves erros de pronúncia ao consulente, seja este aluno, professor, intérprete, secretária bilíngue, ou outros. Entretanto, como mostram os dados, ela é ainda muito pouco explorada, nos dicionários bilíngües.

Em relação aos dicionários monolíngues, constatamos que não dão conta desse aspecto, uma vez que são dicionários de língua destinados a públicos falantes de toda e qualquer LE e, portanto, não são obras que priorizam aspectos que se diferenciam quando contrastados com outros idiomas. Nesse sentido, este não é o seu papel.

Já os dicionários bilíngues, por serem obras elaboradas exatamente com a finalidade de cotejar aspectos de dois idiomas específicos, deveriam contemplar o máximo de informações confrontantes possíveis.

\section{SUBSÍDIOS TEÓRICOS E PRÁTICOS QUE VISAM OTIMIZAR O TRATAMENTO DADO AOS HETEROTÔNICOS DESSAS DUAS LÍNGUAS EM CONTRASTE: REFLEXÕES PARA UMA PEDAGOGIA DOS VOCÁBULOS HETEROTÔNICOS}

Atentando para esse tipo de procedimento (o registro da sílaba tônica dos verbos heterotônicos, em algumas pessoas do presente do indicativo) que o dicionário de Giuseppe Mea faz com maestria, fica evidente que esse tipo de informação, da qual ele dispõe, enriquece a microestrutura de sua obra, visto que acrescenta informações valiosas para o consulente. Todavia, em relação ao dicionário de Amendola - que também se propõe a fornecer esse tipo de informação -, deveria haver mais rigor no registro dessas preciosas informações, já que ele não ocorre de modo sistemático.

É fundamental e necessário que o dicionarista, ainda, detalhe na introdução de sua obra o que representa cada uma das marcas de uso inseridas, de modo a dirimir qualquer dúvida que o consulente possa vir a ter. Isso porque, ao marcar

\footnotetext{
${ }^{11}$ No verbete de visitare, o Amen apresenta a transcrição da primeira pessoa do singular, mas se esquece de marcar a sílaba tônica. 
a sílaba tônica dos verbos heterotônicos, nas pessoas citadas, no Presente do Indicativo, o dicionarista ou lexicógrafo precisa também informar aos usuários que o mesmo procedimento é válido para os tempos Presente do Subjuntivo e Imperativo, nas mesmas pessoas indicadas.

Por fim, no que tange às demais obras investigadas - que não valorizam esse aspecto informativo, a nosso ver utilíssimo e indispensável a qualquer consulente não-nativo - deixamos aqui uma sugestão: registrar sistematicamente e com muito rigor a tonicidade dos verbos heterotônicos, nos tempos e pessoas em que esse fenômeno ocorre, uma vez que o acréscimo dessa valiosa informação não requer tanto espaço físico na obra.

Todavia, na falta desses procedimentos nos dicionários bilíngües, vale uma listagem individual contrastiva entre o português e o italiano, preparada por cada professor, para solucionar problemas com as sílabas tônicas daqueles que fazem uso da língua italiana como LE. Isso porque acreditamos muito na validade de o professor enfocar esse assunto, junto à sua clientela, com seriedade, regularidade e até insistência. O ideal seria que esse procedimento metodológico fosse explorado com freqüência em salas de aula de ensino de língua italiana, inclusive com exercícios contrastivos, para que os alunos, uma vez familiarizados com essa problemática, não cometessem erros primários de pronúncia, por falta de devida atenção do professor a esse aspecto. A gravidade do problema aumenta, não obstante, quando a clientela envolvida freqüenta cursos de Licenciatura ou de Bacharelado em Letras, Interpretação, Secretariado Bilíngüe, e outros, da qual se espera maior qualificação no idioma estudado.

Concluímos esse artigo salientando, mais uma vez, a grande contribuição do dicionário bilíngüe de Giuseppe Mea que, no aspecto da tonicidade das palavras, supera todas as demais obras aqui investigadas, especialmente no tópico que foi objeto deste artigo. Este representa praticamente uma inovação sua, se comparado com quase todas as demais obras que carecem dessa marca.

\section{CONSIDERAÇÕES FINAIS}

Considerando a importância de saber pronunciar corretamente as estruturas lingüísticas de qualquer língua estrangeira (nesse caso, do italiano), percebemos, durante a análise de seis obras bilíngües italiano-português, que apenas duas delas registram a sílaba tônica de um grupo específico de verbos heterotônicos italianos, quando conjugados. Dessas duas obras, apenas o Mea fornece esse tipo de informação de forma sistemática e constante.

Esse grupo específico de verbos italianos, apesar de ser bastante numeroso, não apresenta nenhuma regra ou indício que favoreça a identificação certeira de que se trata de verbos heterotônicos, em relação ao português, quando conjugados no presente do indicativo, do subjuntivo e no Imperativo, na $1^{\mathrm{a}}, 2^{\mathrm{a}}$ e $3^{\mathrm{a}}$ pessoas do singular e na $3^{\mathrm{a}}$ do plural. Disso resulta que a presença dessa informação acaba por 
ser indispensável ao consulente preocupado em desenvolver uma boa pronúncia na língua italiana.

A estratégia de sinalizar a sílaba tônica dos verbos heterotônicos conjugados, apesar de não requerer tanto espaço físico e de ser de fundamental importância nas obras bilíngües italianas, para que se possa evitar graves erros de pronúncia ao consulente, ainda é muito pouco explorada.

Por fim, salientamos que, na falta ou não desse tipo de informação nos dicionários bilíngües, ainda cabe ao professor elaborar sua listagem individual de substantivos, verbos no infinitivo e verbos conjugados nos tempos e pessoas apresentados para, a partir dela, poder criar atividades relevantes que enfoquem este aspecto tão importante da língua italiana e tão ignorado ainda pela maioria dos dicionários bilíngues italiano-português disponíveis no mercado.

\section{$\overline{\text { REFERÊNCIAS BIBLIOGRÁFICAS }}$}

AMARAL, V. L. Análise crítica de dicionários escolares bilingües espanhol-português: uma reflexão teórica e prática. Tese (Doutorado em Filologia e Lingüística). Assis: Faculdade de Ciências e Letras, Unesp, 1995.

AMENDOLA, J. Dicionário italiano português. 2.ed. São Paulo: HEMUS, 1976.

COSERIU, E. Sistema, norma y habla. In: _. Teoria del lenguaje y lingüistica general. Cinco estúdios. 3ed. Madrid: Editorial Gredos, 1978. p. 11-113.

MEA, G. Dizionario italiano-portoghese. Porto: Porto, 1989.

PARLAGRECO, C. Dizionario portoghese-italiano, italiano-portoghese. 5. ed. São Paulo: Martins fontes, 1990 .

POLITO, A. G. - MICHAELIS - pequeno dicionário italiano-português, português-italiano. São Paulo: Melhoramentos, 1993.

SABINO, M. A. Dicionário italiano-português de falsos cognatos e cognatos enganosos: subsídios teóricos e práticos. Araraquara, Tese (Doutorado em Letras: Lingüística e Língua Portuguesa) Faculdade de Ciências e Letras, Universidade Estadual Paulista, 2002, 345p.

SPINELLI, V. \& CASASANTA, M. Dizionario completo italiano-portoghese (brasiliano) e portoghese (brasiliano)-italiano. Parte prima italiano-portoghese (brasiliano). Milão: Ulrico Hoepli, 1983.

ZANICHELLI, ED. Dizionario essenziale portoghese-italiano e italiano-portoghese. Bologna: Zanichelli - Holtkamp \& Whitlam Ltd, 1991.

ZINGARELLI, N. Lo Zingarelli 2000: vocabolario della Lingua Italiana (com CD-ROM). 12. ed. Bologna: Zanichelli, 1999. 